\title{
Summary
}

1. In 374 consecutive extractions there occurred 49 hyphaemata, giving a percentage of $13 \cdot 13$.

2 . Of these, 42 came from the section ( 85 per cent.), and the remainder from the iris and conjunctival flap.

3 . In those that came from the section the average day of occurrence was 3.7 days after the operation, and they took 18.4 days to absorb.

4. The type of operation has no influence on the incidence of hyphaema.

5. No general condition such as diabetes or hyperpiesis has any influence in their occurrence.

6. It is due to local trauma such as squeezing the lids, which causes separation of the wound edges and rupture of the young vessels in the section.

7. They can be prevented by the use of a corneo-scleral stitch.

8. Several factors are enumerated which cause delay in absorption of the blood.

9. The literature is reviewed, and though there is some difference of opinion, most of the younger authors think that they come from the section.

10. The aqueous humour has no action on red cells, but can dissolve fibrin from the clot.

11. The cells are absorbed by the iris, and do not enter the canal of Schlemm.

\section{DISLOCATION OF THE LENSES, WITH OTHER CONGENITAL DEFECTS: SECONDARY GLAUCOMA}

BY

\section{N. BISHOP HARMAN and ROBERT BUXTON \\ LONDON \\ WESTON-SUPER-MARE}

THE subject of these defects is an only child of normal parents. He was noticed to be short-sighted at the age of 3 years. Glasses were ordered by an ophthalmic surgeon at the age of 5 years : right and left $-18 \mathrm{D}$. sphere. At the age of 7 years, he was seen by Mr. R. C. Elmslie on account of his physique. "He had metatarsus varus of severe degree in both feet. This was practically a very mild form of congenital talipes in which the anterior part of the foot only was inverted. His physique was very poor and his posture bad."

N. B. H. saw him in 1928, and ascertained the above facts. 
The media of each eye were clear. The fundi appeared normal. Vision with the glasses was about $6 / 36$. In his notes N. B. H. entered "lenticular dislocation?" He could find no definite evidence of this, but the depth of the anterior chamber suggested it.

In 1931, there was definite evidence of the dislocation of the lenses. The irides were shaky, and the edges of the lenses could just be seen upwards and outwards. The best vision was obtained with $-20 \mathrm{D}$. sph., which gave $6 / 36$ in each eye. With the red green test there was binocular vision. He had been at a small school and was allowed to do the usual work.

In 1934 right vision with - 25D. sph., was $6 / 36$, and the left with $-22 \mathrm{D}$. sph. was $6 / 18$ partly.

In 1936, at the age of 16 years, he was $6 \mathrm{ft}$. 1in. high, unsteady in his movements, and with poor responses. He had suffered with phlebitis in both legs, and from epileptic fits.

In 1938, the aphakic gap in each eye had enlarged. With the right eye, vision was best with +11D. sph., which gave 6/18 partly. With the left eye and +11D. sph. he got $6 / 24$. With an additional $+4 \mathrm{D}$. sphere he could read Jaeger 8 . A few weeks later his mother wrote to say that " he was a new boy with these glasses."

On January 17, 1939, he was seen by R. B. suffering from an attack of acute glaucoma in the right eye, of about 10 hours' duration. There appeared to be a partial dislocation of the lens into the anterior chamber.

Treatment with eserine, medical diathermy and the electric eye warmer was employed, with no improvement. The medical diathermy was 5 metre short-wave diathermy for 10 minutes in the morning and 15 minutes in the afternoon.

$\mathrm{He}$ was seen in consultation with $\mathrm{Mr}$. Anthony Palin next evening who agreed that an operation was essential. Treatment with atropine and the patient supine, was attempted for 3 hours before operation, without success.

R. B. operated under evipan anaesthesia. The lens and vitreous presented as the section was completed. The lens was easily removed in its capsule and the vitreous prolapse well controlled by a corneo-scleral suture. No iridectomy was done.

Fight +9.75D. sph.

Eight weeks later the eye was quiet and with $\frac{1.75 \text { cyl. ax. } 25}{+1.75}$ R.V. $=6 / 18$. With +40D. sph. added R.V.=J. 8 easily.

The rim of the left lens is seen just below the centre of the pupil. L.V. $c+11.0 \mathrm{D}$. sph. $=6 / 18$. The left eye is being kept on a weak miotic, as a precautionary measure. 